\title{
Functional and molecular interactions between the HGF/c-Met pathway and c-Myc in large-cell medulloblastoma
}

\author{
Yunqing Li ${ }^{1}$, Fadila Guessous ${ }^{1}$, Elizabeth B Johnson ${ }^{1}$, Charles G Eberhart ${ }^{2}$, Xiao-Nan Li ${ }^{3}$, Qing Shu ${ }^{3}$, \\ Shongshan Fan ${ }^{4}$, Bachchu Lal ${ }^{6}$, John Laterra ${ }^{5,6}$, David Schiff ${ }^{1}$ and Roger Abounader ${ }^{1,7}$
}

The growth factor hepatocyte growth factor (HGF), also known as scatter factor, and its tyrosine kinase receptor c-Met play important roles in medulloblastoma malignancy. The transcription factor c-Myc is another contributor to the malignancy of these most common pediatric brain tumors. In the present study, we observed strong morphological similarities between medulloblastoma xenografts overexpressing HGF and medulloblastoma xenografts overexpressing c-Myc. We therefore hypothesized a biologically significant link between HGF/c-Met and c-Myc in medulloblastoma malignancy and studied the molecular and functional interactions between them. We found that HGF induces c-Myc mRNA and protein in established and primary medulloblastoma cells. HGF regulated c-Myc levels via transcriptional and posttranscriptional mechanisms as evidenced by HGF induction of c-Myc promoter activity and induction of c-Myc protein levels in the setting of inhibited transcription and translation. We also found that HGF induces cell cycle progression, cell proliferation, apoptosis and increase in cell size in a c-Myc-dependent manner. Activation of MAPK and PI3K, inhibition of GSK-3 $\beta$ and translocation of $\beta$-catenin to the nucleus as well as Tcf/Lef transcriptional activity were involved in mediating c-Myc induction by HGF. Induction of Cdk2 kinase activity was involved in mediating the cell cycle progression effects, and downregulation of Bcl-XL was involved in mediating the proapoptotic effects of HGF downstream of c-Myc. All molecules that mediated the effects of HGF on c-Myc expression, cell proliferation and apoptosis were expressed in human large-cell medulloblastoma tissues. We therefore established for the first time a functional cooperation between HGF/c-Met and c-Myc in human medulloblastoma and elucidated the molecular mechanisms of this cooperation. The findings provide a potential explanation for the high frequency of c-Myc overexpression in medulloblastoma and suggest a cooperative role for c-Met and c-Myc in large-cell anaplastic medulloblastoma formation.

Laboratory Investigation (2008) 88, 98-111; doi:10.1038/labinvest.3700702; published online 3 December 2007

KEYWORDS: c-Met; c-Myc; hepatocyte growth factor; scatter factor; medulloblastoma; embryonal CNS tumors

Medulloblastoma is the most common malignant primary central nervous system tumor of childhood. The molecular mechanisms of progression and metastasis of medulloblastoma are only partially understood. The HedgehogPatched, Wnt, Notch and Trk signaling pathways are recognized to play a role in medulloblastoma tumorigenesis and malignancy. However, these pathways most likely only represent a subset of the mechanisms that underlie the malignancy of these heterogenous and complex tumors. ${ }^{1-3}$ Recently, we established hepatocyte growth factor (HGF) and its tyrosine kinase receptor c-Met signaling as a new pathway of malignancy with multifunctional effects in human medulloblastoma. We showed that c-Met levels statistically significantly correlated with shorter patient survival. We also found that activation of the HGF/c-Met pathway leads to the induction of multiple malignancy parameters, including anchorage-independent growth, cell proliferation, cell cycle progression and cell survival in human medulloblastoma cell lines as well as tumor growth in vivo. ${ }^{4}$ The oncoprotein c-Myc is another adverse prognostic indicator and

\footnotetext{
${ }^{1}$ Department of Neurology, University of Virginia, Charlottesville, VA, USA; ${ }^{2}$ Department of Pathology, The Johns Hopkins University, Baltimore, MD, USA; ${ }^{3}$ Department of Pediatrics, Texas Children's Cancer Center, Baylor College of Medicine, Houston, TX, USA; ${ }^{4}$ Department of Micro/Immunology, University of Rochester Medical Center, Rochester, NY, USA; ${ }^{5}$ Department of Neurology, The Johns Hopkins University, Baltimore, MD, USA; ${ }^{6}$ The Kennedy Krieger Research Institute, Baltimore, MD, USA and ${ }^{7}$ Department of Microbiology, University of Virginia, Charlottesville, VA, USA

Correspondence: Dr R Abounader, MD, PhD, Department of Neurology, University of Virginia, Old Medical School, Room 4819, PO Box 800394, Charlottesville, VA 22908, USA. E-mail: ra6u@virginia.edu
} 
contributor to cell proliferation, differentiation and transformation of human medulloblastoma. ${ }^{5-10} c-M y c$ is activated by genomic amplification in $4-8 \%$ of medulloblastoma and such amplification is associated with worse clinical outcome. Overexpression of c-Myc mRNA is observed in $31-64 \%$ of medulloblastoma. ${ }^{1-16}$ Therefore, the frequency of $c-M y c$ amplification is not sufficiently high to explain the high frequency of overexpression of c-Myc protein in medulloblastoma. It was suggested that mechanisms other than gene amplification may activate $c-M y c$ transcription in these tumors. In other human tumors, previous observations have revealed that growth factors can induce $c-M y c$ expression. Examples include plateletderived growth factor, which controls c-Myc expression through JNK-, AP-1- and Src-dependent mechanisms. ${ }^{17,18}$ Epidermal growth factor (EGF) induces $c-M y c$ expression in embryonic hamster palate mesenchymal cells. ${ }^{19}$ Keratinocyte growth factor or fibroblast growth factor-10 dramatically stimulates the expression of c-Myc protein in a human endometrial carcinoma cell line. ${ }^{20}$ However, the mode and mechanisms of c-Myc overexpression in most human medulloblastoma are still unknown.

In the present study, we first observed that the morphology of medulloblastoma xenografts established from HGF-overexpressing DAOY cells strikingly resembles the morphology of xenografts derived from c-Myc-overexpressing DAOY cells as well as the large-cell medulloblastoma subtype that is associated with $c-M y c$ amplification. ${ }^{21,22}$ We therefore hypothesized a biologically significant link between the HGF/ c-Met pathway and c-Myc in human medulloblastoma malignancy and systematically studied the molecular and functional interactions between them. We found that $c-M y c$ expression is regulated by HGF in established and primary medulloblastoma cells and we elucidated the signal-transduction pathways and transcriptional events that are involved in this process. We found that HGF induces cell proliferation, cell cycle progression, apoptosis and cell size increase in medulloblastoma cells in a c-Myc-dependent manner, which involved Cdk2 kinase and Bcl-XL. This study provides insight into the molecular cooperation between c-Met-dependent pathways and c-Myc as well as into the regulation of c-Myc in medulloblastoma. HGF and/or c-Met overexpression in medulloblastoma could explain the high levels of c-Myc in these tumors.

\section{MATERIALS AND METHODS \\ Cell Culture and Reagents}

DAOY human medulloblastoma cells were grown in improved minimum essential medium zinc option supplemented with $10 \%$ fetal bovine serum (FBS). DAOY-HGF cells overexpressing HGF and DAOY-control cells have been previously described and were grown in zeocin selection medium. ${ }^{4}$ ONS-76 cells were grown in RPMI 1640 medium supplemented with $10 \%$ FBS. Primary human medulloblastoma cells were isolated from an anaplastic medulloblastoma surgical specimen and grown in neurobasal medium supplemented with EGF ( $50 \mathrm{ng} / \mathrm{ml})$, bFGF ( $50 \mathrm{ng} /$ $\mathrm{ml}$ ), N-2 supplement and B-27 supplement (Invitrogen, Carlsbad, CA, USA). All cells were grown at $37^{\circ} \mathrm{C}$ in $5 \% \mathrm{CO}_{2} /$ $95 \% \mathrm{O}_{2}$. The PI3K inhibitor wortmannin, the MAPK inhibitor U0126 and the broad-spectrum caspase inhibitor (Z-VAD-FMK) were obtained from Calbiochem (San Diego, CA, USA). The protein synthesis inhibitor cyclohexamide and the mRNA transcription inhibitor actinomycin D were obtained from Sigma (St Louis, MO, USA). All inhibitors except cyclohexamide and actinomycin D were added for $1 \mathrm{~h}$ before the cells were treated with human recombinant HGF (100 ng/ ml) (a kind gift from Genentech Inc.). Cyclohexamide and actinomycin D were added to the cells simultaneously with HGF $(100 \mathrm{ng} / \mathrm{ml})$. Camptothecin (CPT) was obtained from Sigma, and Annexin V-PE and Annexin V-FITC were obtained from BD Pharmingen (San Diego, CA, USA).

\section{Vectors and Transfections}

Tcf-responsive luciferase reporter plasmid (pTCF-Luc), mutant Tcf-binding sites luciferase reporter plasmid (pTCFMut-Luc), $\beta$-catenin expression plasmid $\mathrm{p} \beta$-catenin and c-Myc promoter-luciferase reporter plasmid (pDel-1-Luc) were kindly provided by Dr Bert Vogelstein, Johns Hopkins University. ${ }^{23,24} \mathrm{Tcf} /$ Lef transcription factor decoy oligodeoxynucleotides were designed against the $\beta$-catenin/Tcf/Lef consensus binding sequence and scrambled oligodeoxynucleotides were used as control. The decoys were previously tested and shown to inhibit Tcf-Luciferase activity (unpublished data). The Bcl-XL expression vector is a kind gift from Dr Saijun Fan, Lombardi Cancer Center. All cells (50-70\% confluence) were transfected with Fugene-6 transfection reagent (Roche, Indianapolis, IN, USA) according to the manufacturer's specifications with a 3:1 ratio of transfection reagent volume to DNA mass.

\section{Adenovirus Infections}

Adenoviruses encoding anti-c-Met U1/ribozymes were designed and constructed by us as previously described. ${ }^{25}$ Adenovirus vectors encoding c-Myc, the c-Myc dominantnegative MadMyc or GFP were kindly provided by Dr Bert Vogelstein, Johns Hopkins University. ${ }^{24,26}$ An adenovirus vector encoding constitutively active GSK-3 $\beta$ S9A mutant was generated as previously described. ${ }^{27}$ This mutant contains a serine-to-alanine substitution at residue 9 and cannot be inhibited by phosphorylation. The cells were infected with adenovirus vectors $(\mathrm{MOI}=10)$ for $24 \mathrm{~h}$ prior to treatment with HGF. Adenoviruses expressing GFP only $(\mathrm{MOI}=10)$ were used as control in all adenovirus infection experiments.

\section{Northern Analysis}

Total RNA was isolated using the RNeasy Mini Kit (Qiagen, Valencia, CA, USA) following the manufacturer's instructions. Northern analysis was performed as previously reported. ${ }^{25}$ Briefly, blots were hybridized with full-length cDNA probes for $c-M y c$ (a gift of C Dang, Johns Hopkins 
University School of Medicine), and 28S rRNA labeled with $\left[{ }^{32} \mathrm{P}\right] \mathrm{dCTP}$ by a random priming kit (Boehringer-Mannheim, Indianapolis, IN, USA) according to the manufacturer's instructions. Radioactivity was quantified by phosphoimaging using the Bio-Imaging analyzer BAS 2500 (Fuji Medical Systems, Stamford, CT, USA). The blots were stripped and then rehybridized with cDNA specific for $28 \mathrm{~S}$ rRNA. The results were expressed relative to $28 \mathrm{~S}$ rRNA.

\section{Immunoblotting and Immunoprecipitation}

Immunoblotting was performed as previously described using antibodies specific for phospho-c-Met, phospho-MAPK, total MAPK, phospho-Akt, total Akt, phospho-GSK $\alpha / \beta$, GSK $\alpha, \operatorname{GSK} \beta, \beta$-catenin, cleaved-PARP, cleaved-caspase-3, cleaved-caspase-9, Bcl-XL (Cell Signaling Technologies, Danvers, MA, USA), Cdk2, cyclin E, E2F-1, c-Myc (Santa Cruz Biotechnologies, Santa Cruz, CA, USA) and p27 (BD Biosciences, San Jose, CA, USA). ${ }^{4}$ Blots were also hybridized with $\beta$-actin (Santa Cruz Biotechnologies) as loading control. Blots that did not exhibit protein expression changes of large magnitude were quantified by densitometry on film and quantified protein was expressed relative to $\beta$-actin with control set at 1 . Immunoprecipitations of cyclin $\mathrm{E}$ were used to determine Cdk2 protein levels in cyclin E/ Cdk2 complexes, and were performed as follows. For immunoprecipitation, DAOY cells were plated in $10 \%$ FBS medium. The following day, cells were exposed to $0.1 \%$ FBS medium and infected with adenoviruses expressing MadMyc or GFP (control) for $24 \mathrm{~h}$ prior to treatment with HGF for $24 \mathrm{~h}$. The cells were then lysed with RIPA buffer (1\% Igepal, $0.5 \%$ sodium deoxycholate and $0.1 \%$ SDS in PBS) and lysates were cleared by centrifugation. The protein concentration of the supernatant was determined. Each sample $(500 \mu \mathrm{g}$ of total protein) was subjected to a preclear step with a normal mouse IgG-conjugated agarose beads (Santa Cruz Biotechnologies) for $30 \mathrm{~min}$ and then immunoprecipitated with $30 \mu \mathrm{l}$ cyclin E-conjugated agarose beads (Santa Cruz Biotechnologies) overnight at $4^{\circ} \mathrm{C}$. The beads were collected by centrifugation, washed five times with lysis buffer, heated to $100^{\circ} \mathrm{C}$ in Laemmli buffer, and subjected to immunoblotting for Cdk2 as described above.

\section{Immunofluorescence and Immunohistochemistry}

The cellular localization of $\beta$-catenin was determined by immunofluorescence. DAOY cells were plated on coverslips in $10 \%$ FBS medium for $24 \mathrm{~h}$ and subsequently exposed to $0.1 \%$ FBS medium for $24 \mathrm{~h}$ prior to treatment with or without HGF for $30 \mathrm{~min}$. The cells were fixed with $4 \%$ paraformaldehyde for $10 \mathrm{~min}$ and permeabilized with $7.5 \%$ glycine containing $0.5 \%$ Triton-100 for overnight. The cells were then incubated with rabbit polyclonal anti-human $\beta$-catenin antibody in staining solution (1\% BSA with $0.1 \%$ $\mathrm{NP}-40)$ for $2 \mathrm{~h}$ and then incubated with FITC-conjugated donkey anti-rabbit secondary antibody for $30 \mathrm{~min}$. Coverslips were put on slides with Vectashield Antifade solution with
DAPI (Vector Laboratories, Burlingame, CA, USA). Immunofluorescent localization of $\beta$-catenin was analyzed with an Axiovision fluorescent microscope.

Immunohistochemistry was used to ascertain the expression of key molecules linking c-Met and c-Myc in human large-cell medulloblastoma tissues. Tissue arrays containing multiple sections from 100 cases of embryonal central nervous system tumors including 20 large-cell anaplastic medulloblastoma as well as normal tissues including cerebellum were used for these experiments. The tissue arrays were developed and characterized by Dr Charles Eberhart, Johns Hopkins University. Immunohistochemical staining was performed on a DAKO Autostainer using DAKO DAB + and substrate as the chromagen. Deparaffinized sections of formalin-fixed tissues were immunostained using antibodies specific for HGF, c-Met and Cdk2 (Santa Cruz Biotechnologies), Akt, MAPK and Bcl-XL (Cell Signaling Technologies) and $\beta$-catenin (Epitomics Inc., Burlingame, CA, USA) after $10 \mathrm{mM}$ citrate $(\mathrm{pH}$ 6) retrieval in DAKO Pascal Pressure Chamber for $0.5 \mathrm{~min}$. Appropriate negative (no primary antibody) and positive controls (human colon cancer) were stained in parallel with each set of tumors studied.

\section{Luciferase Assays}

To measure $c-M y c$ promoter and Tcf/Lef transcriptional activity, DAOY and ONS-76 cells were seeded in six-well plates and transfected as described above with $2 \mu \mathrm{g}$ of either pDel-1Luc, pTCF-Luc plasmid DNA, pTCF-Mut-Luc plasmid DNA as negative control or $1 \mu \mathrm{g}$ of $\mathrm{p} \beta$-catenin plasmid DNA as positive control. At $24 \mathrm{~h}$ after transfection, cells were exposed to $0.1 \%$ FBS medium overnight and stimulated with or without HGF for 1-6 h. Cell extracts were prepared with $50 \mu \mathrm{l}$ reporter lysis buffer (Promega, Madison, WI, USA). Luminescence was measured in $10 \mu \mathrm{l}$ of cell extract with a luciferase assay system kit (Promega) using a luminometer (Monolight 2010). Activity was expressed as fold change in relative light units per $\mathrm{mg}$ of cellular protein as determined by the Coomassie protein assay (Pierce, Rockford, IL, USA).

\section{Propidium lodide Flow Cytometry}

The effects of HGF and c-Myc on cell cycle progression were assessed using propidium iodide (PI) flow cytometry as previously described. ${ }^{4}$ Briefly, DAOY or ONS-76 cells were grown in $10 \%$ FBS medium for $24 \mathrm{~h}$ and subsequently exposed to $0.1 \%$ FBS. Both cell types were infected with adenoviruses expressing c-Myc, MadMyc or GFP (control) for $24 \mathrm{~h}$ prior to treatment without or with HGF for $24 \mathrm{~h}$. The treated cells were washed with PBS, harvested and fixed in $70 \%(\mathrm{v} / \mathrm{v})$ ethanol. The cells were then treated with $20 \mu \mathrm{g}$ of DNase-free RNase and stained with PI. Cell samples were analyzed on a FACscan (Becton-Dickinson, Fullerton, CA, USA). 


\section{Annexin V Flow Cytometry}

Annexin V flow cytometry was used to test the effect of HGF on radiotherapy- or chemotherapy-induced apoptosis as previously described. ${ }^{4}$ Briefly, $1 \times 10^{5}$ DAOY cells were seeded in $35 \mathrm{~mm}$ plates in $10 \%$ serum and subsequently preincubated with or without HGF for $48 \mathrm{~h}$ prior to treatment with CPT (100-500 $\mathrm{nM})$ or $\gamma$-radiation (20-40 Gy) for $48 \mathrm{~h}$. The fraction of phosphatidylserine-positive cells was determined by flow cytometry using the Annexin V-FITC Detection Kit according to the manufacturer's instructions.

\section{Cell Size Assay}

Flow cytometry was used to determine the effects of HGF treatment on cell size in vitro and its dependency on c-Myc. DAOY cells were plated in 10\% FBS medium. The following day, the cells were exposed to $0.1 \%$ FBS medium and infected with adenoviruses encoding MadMyc or GFP (control) for $24 \mathrm{~h}$ prior to treatment with $10 \mathrm{ng} / \mathrm{ml} \mathrm{HGF}$ for $48 \mathrm{~h}$. The cells were collected and prepared for cell cycle analysis as described above. Cell sizes were analyzed on a FACS Calibur flow cytometer using the parameter mean forward scatter height (FSC-H), which is a measure of relative cell size.

\section{Lactate Dehydrogenase Assays}

Lactate dehydrogenase (LDH) assays were performed to further confirm the proapoptotic effect of HGF as previously described. ${ }^{4}$ Briefly, $1 \times 10^{4}$ cells per well were plated in 12 well plate. Cells were then preincubated with or without HGF for $48 \mathrm{~h}$ in $10 \%$ serum and subsequently treated with CPT $(100-500 \mathrm{nM})$ for $48 \mathrm{~h}$. Cells in each well were assayed for LDH release using CytoTox96NonRadioactive Cytotoxicity Assay (Promega). Cells were also pretreated with broadspectrum caspase inhibitor (Z-VAD-FMK, $100 \mu \mathrm{M}$ ) for $1 \mathrm{~h}$ prior to incubation with HGF and treatment with CPT $(250 \mathrm{nM})$. The fraction of cell death was determined by $\mathrm{LDH}$ assays.

\section{PI and Trypan Blue Staining}

The apoptotic effects of HGF and c-Myc were also analyzed by PI and trypan blue staining. DAOY cells were infected with adenoviruses expressing c-Myc, MadMyc or GFP (control) for $24 \mathrm{~h}$ as described above and subsequently preincubated with or without HGF for $48 \mathrm{~h}$ prior to treatment with CPT $(100 \mathrm{nM})$ for $24 \mathrm{~h}$. MadMyc was also transfected into DAOYHGF or DAOY-control clones and cells were treated with or without $100 \mathrm{nM} \mathrm{CPT}$. All cells were subsequently stained with trypan blue. The number of dead cells stained with trypan blue was determined by counting with a hemocytometer. To obtain morphological evidence of apoptosis, the cells were stained with a solution of PI in PBS $(10 \mu \mathrm{g} / \mathrm{ml})$. Cell suspensions were mounted on slide glasses and subjected to fluorescence microscopic examination. The dead cells can be identified by positive red fluorescence as PI penetrates the membranes of dying/dead cells and intercalates into the major groove of the DNA and produces a fluorescent adduct.

\section{Growth Curves}

To determine the effects of HGF and c-Myc on cell proliferation, 30000 DAOY cells per well were seeded in six-well plates. At $24 \mathrm{~h}$ after infection with adenovirus vectors encoding MadMyc or GFP (control), the cells were treated with or without HGF. The cells were harvested by trypsinization every day for 5 days and counted with a hemocytometer.

\section{Cyclin-Dependent (Cdk2) Kinase Assay}

A kinase assay was used to determine if $\mathrm{c}-\mathrm{Myc}$ mediates HGF-induced cell cycle progression via activation of Cdk2 kinase activity in DAOY cells. DAOY cells were treated similar to cyclin $\mathrm{E}$ immunoprecipitations described above. Each sample ( $500 \mu \mathrm{g}$ of total proteins) was subjected to a preclear step with a normal mouse IgG-conjugated agarose beads (Santa Cruz Biotechnologies) for $30 \mathrm{~min}$ and then immunoprecipitated with $30 \mu \mathrm{l}$ cyclin E-conjugated agarose beads (Santa Cruz Biotechnologies) for $1 \mathrm{~h}$ at $4^{\circ} \mathrm{C}$. The beads were collected by centrifugation, washed three times with lysis buffer and twice with kinase buffer containing $50 \mathrm{mM}$ Tris-Hcl ( $\mathrm{pH}$ 8.0), $8 \mathrm{mM} \mathrm{MgCl}_{2}, 1 \mathrm{mM}$ DTT and protease inhibitor cocktail, and subsequently incubated for $30 \mathrm{~min}$ at $30^{\circ} \mathrm{C}$ in $30 \mu \mathrm{l}$ of kinase reaction mixture containing $1 \mu \mathrm{g} / \mu \mathrm{l}$ histone $\mathrm{H1}, 50 \mu \mathrm{M}$ ATP (Upstate, Lake placid, NY, USA) and $5 \mu \mathrm{Ci}$ of $\left[\gamma^{32} \mathrm{P}\right] \mathrm{ATP}$ (Amersham-Pharmacia). After the incubation, $6 \times$ Laemmli loading buffer was added to each sample, the complexes were dissociated by heating to $100^{\circ} \mathrm{C}$ for $5 \mathrm{~min}$, and the reaction products were subjected to SDSPAGE. The gel was subsequently dried, and the phosphorylated histone product was visualized and quantified by phosphoimaging (Fujifilm).

\section{Bcl-XL Assays}

To determine if Bcl-XL mediates the proapoptotic effects of HGF, Bcl-XL was forcibly overexpressed in DAOY cells prior to determination of the effects of HGF on apoptosis. For this purpose, DAOY cells were seeded in $35 \mathrm{~mm}$ plates in $10 \%$ FBS. Cells were then cotransfected with $3 \mu \mathrm{g} \mathrm{Bcl-XL} \mathrm{cDNA}$ and $1 \mu \mathrm{g}$ GFP cDNA (3:1) for $6 \mathrm{~h}$. The transfected cells were subsequently treated with HGF for $48 \mathrm{~h}$ prior to treatment with CPT $(250 \mathrm{nM})$ for $48 \mathrm{~h}$. Bcl-XL-positive cells were determined via selection for GFP. GFP-positive cells were analyzed for apoptosis with Annexin-PE by flow cytometry according to the manufacturer's instructions.

\section{Statistics}

All immunoblots show representative results from at least two experiments. All other experiments were repeated at least three times and the results were expressed as mean \pm s.e.m. When appropriate, two group comparisons were analyzed with a $t$-test and multiple group comparisons were analyzed with a Dunnett's test and $P$-values were calculated. $P<0.05$ was considered significant and symbolized by an asterisk in the graphs. 


\section{RESULTS \\ HGF Overexpression in Medulloblastoma Xenografts Mimics the Morphology of c-Myc-Overexpressing Medulloblastoma Xenografts}

In a previous study, we established human medulloblastoma xenografts from DAOY cells overexpressing HGF (DAOYHGF). When the histologic characteristics of these xenografts were examined, they exhibited dramatic morphological changes compared with DAOY-control xenografts. Interestingly, DAOY-HGF xenografts displayed features that somewhat resembled those of DAOY overexpressing c-Myc xenografts as well as those reported in the human large-cell anaplastic medulloblastoma subtype, which possesses the worst prognosis of all medulloblastomas and is associated with $c-M y c$ amplification ${ }^{21,28}$ (Figure 1). DAOY-HGF cells were, however, smaller and had nuclei with rather indistinct nuclear chromatin compared to DAOY-Myc cells, which more closely resembled the large-cell medulloblastoma with larger cells, larger nuclei and more prominent nucleoli than DAOY-HGF.

\section{HGF Induces c-Myc via Transcriptional and Post-Transcriptional Mechanisms}

The effects of HGF on c-Myc mRNA and protein were assessed by northern analysis and immunoblotting, respectively. Treatment of DAOY cells with HGF $(100 \mathrm{ng} / \mathrm{ml})$ induced c-Myc mRNA levels in a time-dependent manner. The induction of c-Myc mRNA started $15 \mathrm{~min}$ after stimulation with HGF and increased more than four-fold after $120 \mathrm{~min}$ of stimulation before decreasing to nearly basal levels after $4 \mathrm{~h}$ (Figure 2a). HGF induced c-Myc protein levels in DAOY cells in a time-dependent manner (Figure 2b). c-Myc protein induction started as early as $15 \mathrm{~min}$ after stimulation and consistently increased for at least $120 \mathrm{~min}$. Conversely, inhibition of c-Met expression in DAOY cells by infection with adenoviruses encoding anti-c-Met U1/ribozymes completely inhibited HGF-induced c-Myc protein levels. HGF also in- duced c-Myc protein levels in primary medulloblastoma cells and in the medulloblastoma cell line ONS-76 (Figure 2b). Based on the observation that HGF induces c-Myc protein at least as early as it induces c-Myc mRNA, we speculated that HGF might induce c-Myc levels both transcriptionally and post-transcriptionally. To ascertain that HGF transcriptionally induces c-Myc, DAOY cells were transfected with a c-Myc promoter-luciferase vector (pDel-1Luc), treated with HGF and assessed for $c-M y c$ promoter activation by measuring luminescence per unit protein. HGF significantly induced c-Myc promoter-luciferase activity by $>4$-fold $(n=6 ; P<0.01)$, confirming that HGF transcriptionally induces c-Myc in these cells. To determine if induction of c-Myc by HGF also has a post-transcriptional component, DAOY cells were cotreated with HGF and either the protein synthesis inhibitor cyclohexamide $(100 \mathrm{ng} / \mu \mathrm{l})$ or the mRNA transcription inhibitor actinomycin D $(5 \mathrm{ng} / \mu \mathrm{l})$ (Figure 2c). In the setting of inhibited transcription or translation, HGF still induced c-Myc levels after 20 min of treatment. In fact, while c-Myc protein levels in control DAOY cells continuously decreased after treatment with cyclohexamide or actinomycin D, HGF treatment led to an increase of c-Myc protein after 10-20 min. This demonstrates that HGF also affects c-Myc levels post-transcriptionally. This conclusion is also supported by the observation that HGF strongly increases the levels of transgenic c-Myc that is expressed via a constitutive CMV promoter (Figure 2c).

\section{HGF Induces Cell Cycle Progression, Cell Proliferation, Apoptosis and Cell Size Increase in Medulloblastoma Cells in a c-Myc-Dependent Manner}

We have previously shown that HGF allows DAOY and ONS76 medulloblastoma cells to escape G0/G1 cell cycle arrest induced by serum withdrawal and induces DAOY cell proliferation. ${ }^{4}$ Here, we first show that HGF enhances chemotherapy- and radiation-induced apoptosis of DAOY cells. Using Annexin V-FITC flow cytometry as well as an

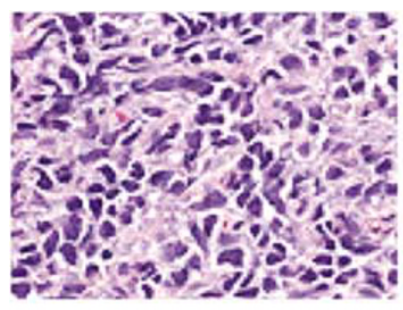

DAOY-Control

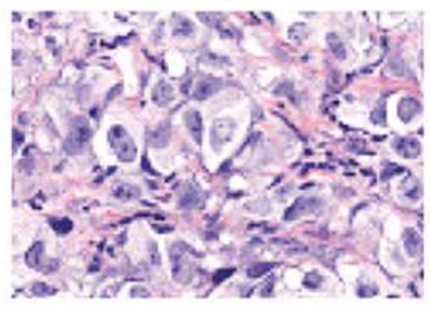

DAOY-SF

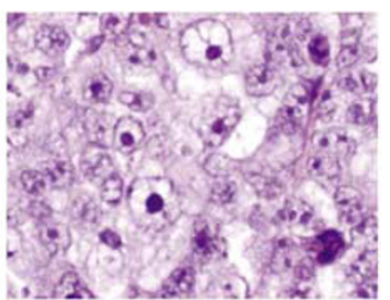

DAOY-MYC

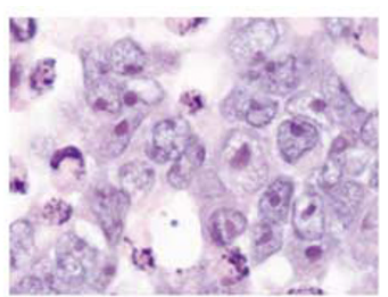

Large Cell Medulloblastoma

Figure 1 HGF overexpression in medulloblastoma xenografts induces morphological changes that strongly resemble the changes observed in medulloblastoma xenografts overexpressing c-Myc. HGF-overexpressing and c-Myc-overexpressing medulloblastoma DAOY cells were stereotactically injected into the brains of immunodeficient mice. The animals were killed after 3 weeks. Histologic analysis of DAOY-HGF xenografts and DAOY-Myc

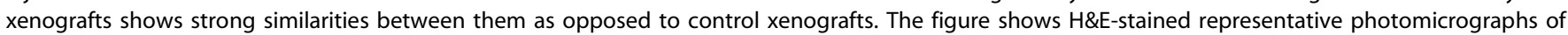
tumor cross-sections originating from DAOY-HGF, DAOY-Myc and DAOY-control cells in comparison with a cross-section of human large-cell anaplastic medulloblastoma tumor ( $\times 100$ magnification for all sections). DAOY-Myc and to a lesser extent DAOY-HGF cross-sections display enlarged cells with large nuclei and prominent nucleoli. These features are also seen in the human medulloblastoma large-cell anaplastic subtype. 
a

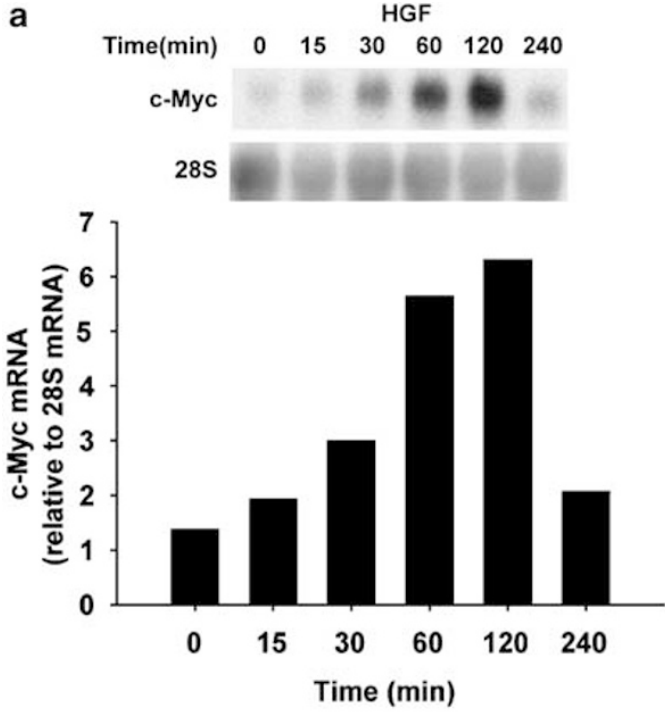

b

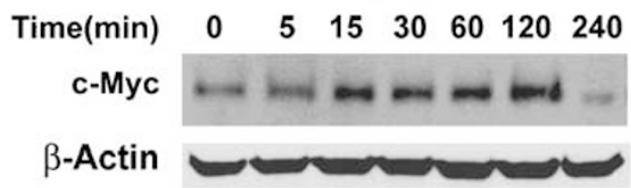

ONS-76 Primary

HGF
c-Myc

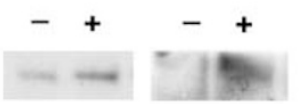

c

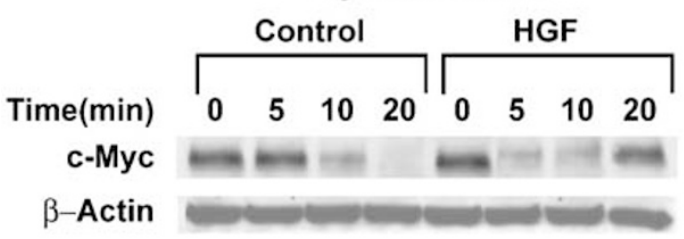

Actinomycin D

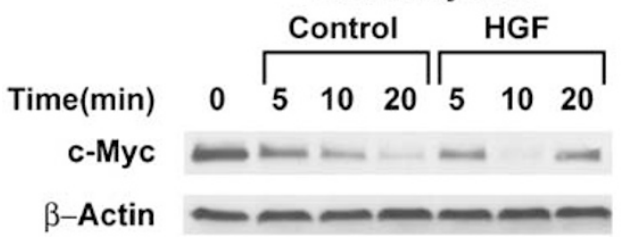

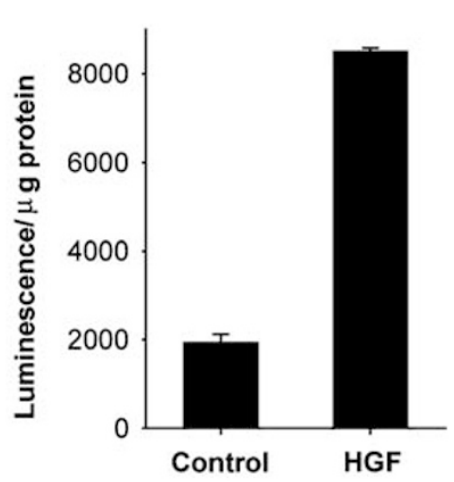
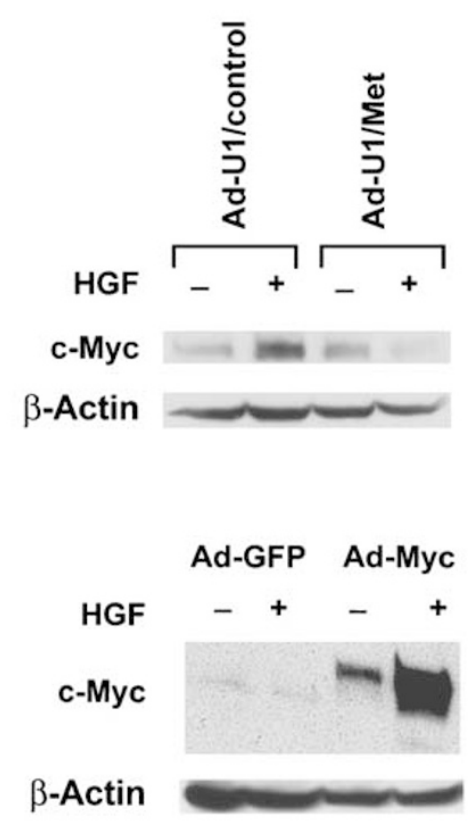

Figure 2 HGF induces C-Myc expression via transcriptional and post-transcriptional mechanisms. (a) Left panel: DAOY medulloblastoma cells were treated with HGF for various time points and c-Myc mRNA levels were measured by quantitative northern analysis. Northern blots show that HGF induces c-Myc mRNA transcription starting at 15 min post-stimulation. Right panel: DAOY cells were transfected with a c-Myc promoter-luciferase plasmid (pDel-1Luc) prior to treatment with HGF. Luciferase assays show that HGF significantly induces c-Myc promoter luciferase activity. (b) Left panels: DAOY, ONS-76 and primary medulloblastoma cells were grown in $0.1 \%$ FBS for $24 \mathrm{~h}$ prior to stimulation with HGF $(100 \mathrm{ng} / \mathrm{ml})$ for various time points. Immunoblotting for c-Myc shows that HGF induces c-Myc protein levels starting as early as $15 \mathrm{~min}$ in DAOY, ONS-76 and primary medulloblastoma cells. Right panel: c-Met was inhibited in DAOY cells by infection with adenoviruses encoding anti-c-Met U1/ ribozymes (Ad-U1/Met or control (Ad-U1/ control) prior to treatment with HGF. Immunoblots show that inhibition of c-Met expression leads to inhibition of HGFmediated induction of c-Myc protein. (c) Immunoblotting for c-Myc shows that HGF can still induce c-Myc protein level after inhibition of protein and mRNA synthesis with cyclohexamide and actinomycin $D$, respectively (left panels). Immunoblotting for c-Myc in DAOY cells infected with adenoviruses expressing c-Myc or GFP prior to stimulation with HGF showing that HGF strongly increases exogenous c-Myc expression relative to control (right panel). Blots are representative from at least two different experiments.
LDH assay, we found that preincubation of DAOY cells with HGF for $48 \mathrm{~h}$ renders the cells more sensitive to either CPT or $\gamma$-radiation and increases the number of apoptotic cells in a dose-dependent manner (Figure 3a).

To determine if c-Myc mediates the effects of HGF on cell cycle, cell proliferation, apoptosis and cell size, we inhibited c-Myc by infecting DAOY and ONS-76 cells with adeno- viruses encoding the c-Myc dominant-negative MadMyc and then studied the effects of HGF on cell cycle progression (DAOY and ONS-76), cell proliferation, apoptosis and cell size (DAOY). We also assessed the effects of MadMyc on cell death in stable DAOY-HGF clones. Cell cycle flow cytometry results show that in the presence of MadMyc, HGF-induced cell cycle progression was inhibited. In control-transfected 
cells, HGF reduced the G1/G0 fraction from $66.6 \pm 0.4$ to $50.3 \pm 1.7 \%$ in DAOY cells and from $78.1 \pm 0.8$ to $67.7 \pm 2.7 \%$ in ONS-76 cells. In MadMyc-transfected cells, HGF reduced the G1/G0 fraction from $76.0 \pm 3.1$ to $70.7 \pm 0.95 \%$ in DAOY cells and did not induce cell cycle progression in ONS-76 cells. Conversely, c-Myc overexpression further enhanced HGF-mediated induction of cell cycle progression in DAOY cells and reduced the G0/G1 fraction from $50.3 \pm 1.7$ to $40.7 \pm 2.0 \%$ (Figure 3b). c-Myc alone induced cell cycle progression leading to a reduction in the G0/G1 fraction from $66.6 \pm 0.4$ in control-infected cells to $56.2 \pm 1.8 \%$ in c-Myc-infected cells. Similarly, inhibition of c-Myc by MadMyc inhibited the cell proliferative effects induced by HGF. While control-transfected DAOY cells numbers increased $\sim 7$-fold after 4 days of exposure to HGF, MadMyc-infected cell numbers increased three-fold after HGF stimulation for the same period of time (Figure 3b). This demonstrates that HGF induction of cell cycle progression and cell proliferation in DAOY cells is partly c-Myc-dependent. c-Myc also mediated the proapoptotic effects of HGF in DAOY cells as measured by PI and trypan blue staining. In the presence of MadMyc, the proapoptotic effect of HGF was inhibited by $\sim 2.6$-fold. HGF increased the fraction of dead cells from $31.3 \pm 4.5$ to $45.1 \pm 1.9 \%$ in control-transfected cells and from $27.9 \pm 1.3$ to $33.3 \pm 3.5 \%$ in MadMyc-infected cells. Overexpression of c-Myc by infection with c-Myc-expressing adenoviruses rendered DAOY cells more sensitive to HGF and led to an increase in cell death from $45.1 \pm 1.9$ to $65.5 \pm 3.5 \%$ (Figure 3c). Also, DAOY-HGF clones had significantly higher basal $(38.9 \pm 1.5 \%)$ and CPT-enhanced $(63.7 \pm 4.3 \%)$ cell death than DAOY-control clones without $(28.8 \pm 2.2 \%)$ or with $(39.7 \pm 2.9 \%)$ CPT $(n=4 ; P<0.05)$. MadMyc completely inhibited the increase in cell death induced by HGF overexpression with or without CPT treatment. This demonstrates that HGF enhances basal and CPT-induced cell death in a c-Myc-dependent manner. Treatment of DAOY cells with HGF led to a moderate but consistent increase in cell size as assessed by flow cytometry $(n=3)$. HGF-induced increase in cell size was completely inhibited by MadMyc (Figure 3d). This shows that HGF-induced cell size increase in medulloblastoma cells is mediated by c-Myc.

\section{HGF Activates Signal Transcription Pathways Upstream of c-Myc}

The effects of HGF on signaling pathways known to mediate the induction of c-Myc in other biological systems were analyzed in DAOY and primary medulloblastoma cells. These pathways include MAPK, PI3K, Akt, GSK-3 and $\beta$-catenin. Also, the $c-M y c$ promoter possesses a Tcf/Lef-binding site known to induce $c-M y c$ transcription. Immunoblotting results show that HGF strongly induced c-Met, MAPK and Akt phosphorylation after 2-60 min of stimulation of primary medulloblastoma and DAOY cells and GSK-3 phosphorylation of DAOY cells after 15-120 min of stimulation (Figure 4a). Immunofluorescence micrographs of DAOY cells demonstrate the redistribution of $\beta$-catenin from cell membrane to cytosol and nucleus after $30 \mathrm{~min}$ of HGF stimulation (Figure 4b). HGF also induced Tcf/Lef-dependent transcriptional activity in DAOY cells transfected with a Tcf/Lefpromoter luciferase reporter. HGF significantly induced Tcf/ Lef-promoter luciferase activity by 1.8 -fold light units relative to protein concentration as measured by a luciferase assay $(n=3, P<0.01)$ (Figure $4 \mathrm{~b})$. These data show that HGF transiently activates signaling molecules upstream of c-Myc, including c-Met, PI3K, MAPK, GSK-3, $\beta$-catenin and Tcf/Lef-dependent transcriptional activity.

\section{MAPK, PI3K and GSK-3 $\beta$ as well as $\beta$-Catenin Transcriptional Activity are Involved in HGF-Mediated Induction of c-Myc}

To determine if MAPK, PI3K, GSK-3 $\beta$ and $\beta$-catenin/Tcf/ Lef-dependent transcriptional activity mediate the HGF induction of c-Myc, these molecules were inhibited/activated in DAOY cells prior to treatment with HGF and the effects of activation/inhibition on HGF induction of c-Myc were

Figure 3 HGF induces cell cycle progression, cell proliferation, apoptosis and increased cell size in human medulloblastoma cells in a c-Myc-dependent manner. (a) Flow cytometric analysis of Annexin V-FITC-labeled DAOY cells that were pretreated with HGF before treatment with CPT or $\gamma$-radiation. The results show that HGF increases the fraction of apoptotic cells (left two panels). LDH assay also shows that HGF increases the fraction of the dead cells triggered by CPT in DAOY cell treated as described above (right panel). (b) Flow cytometric analysis of the cell cycle in DAOY and ONS-76 cells infected with adenoviruses expressing c-Myc, MadMyc or GFP (control) prior to stimulation with HGF. The results show that inhibition of c-Myc with MadMyc inhibits the HGF-mediated induction of cell cycle progression and that overexpression of c-Myc synergizes with HGF induction of cell cycle progression (left two panels). DAOY cells were infected with adenoviruses expressing MadMyc or GFP prior to stimulation with HGF. Cells were counted for 5 days and growth curves were established. The results show that inhibition of c-Myc with MadMyc leads to inhibition of HGF-induced cell proliferation (right panel). (c) Left and middle panels: DAOY cells were infected with adenoviruses as in 'panel b' before stimulation with HGF and treatment with CPT. Representative PI staining (left panel) shows that MadMyc expression inhibits HGF-induced cell death. Trypan blue staining-based quantification of dead cells (middle panel) shows that inhibition of c-Myc with MadMyc inhibits the proapoptotic effects of HGF and that overexpression of c-Myc increases the proapoptotic effects of HGF. Right panel: DAOY-HGF and DAOY-control stably transfected clones were infected with MadMyc or control adenoviruses, treated with or without CPT and subsequently assessed for cell death by trypan blue staining. The data show that MadMyc inhibits HGF-induced cell death in the cells. (d) DAOY cells were infected with adenoviruses encoding MadMyc or GFP-control for $24 \mathrm{~h}$ prior to treatment with $10 \mathrm{ng} / \mathrm{ml} \mathrm{HGF}$ for $48 \mathrm{~h}$. Cell sizes were analyzed on a FACS Calibur flow cytometer using the parameter mean FSC-H, which is a measure of relative cell size. The data show that HGF induces a rightward shift (cell size increase) of the curve of HGF-treated cells and that MadMyc completely inhibits it. ${ }^{\star} P<0.05$ relative to control. 
assessed by quantitative immunoblotting. Inhibition of MAPK with U0126 and PI3K with wortmannin completely inhibited HGF induction of c-Myc in DAOY cells (Figure 4c).
Constant GSK- $3 \beta$ activity achieved by infection of the cells with adenoviruses expressing GSK-3 $\beta$ mutant S9A, which cannot be inhibited by phosphorylation, led to the partial a

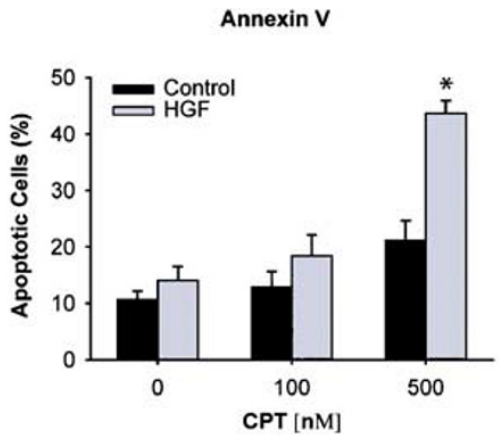

b

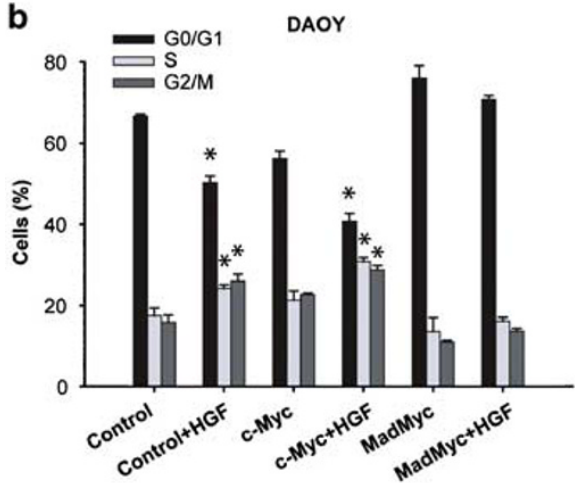

C
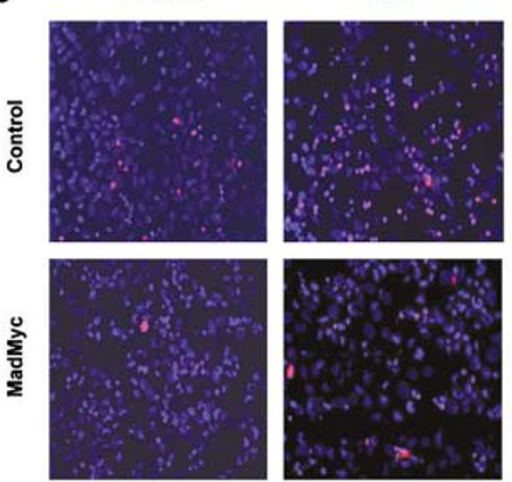

CPT, 250nM

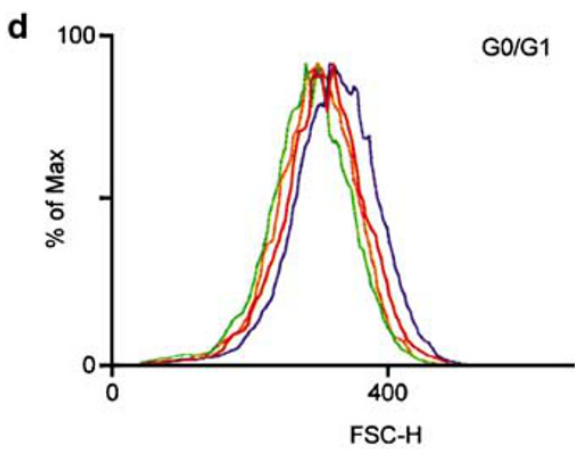

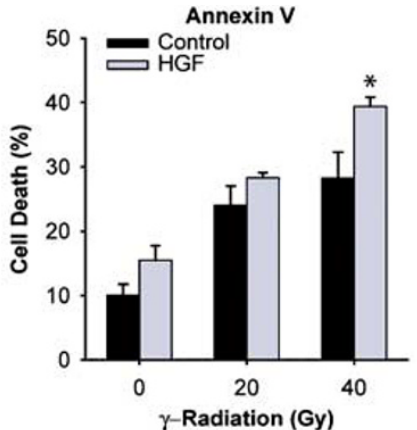
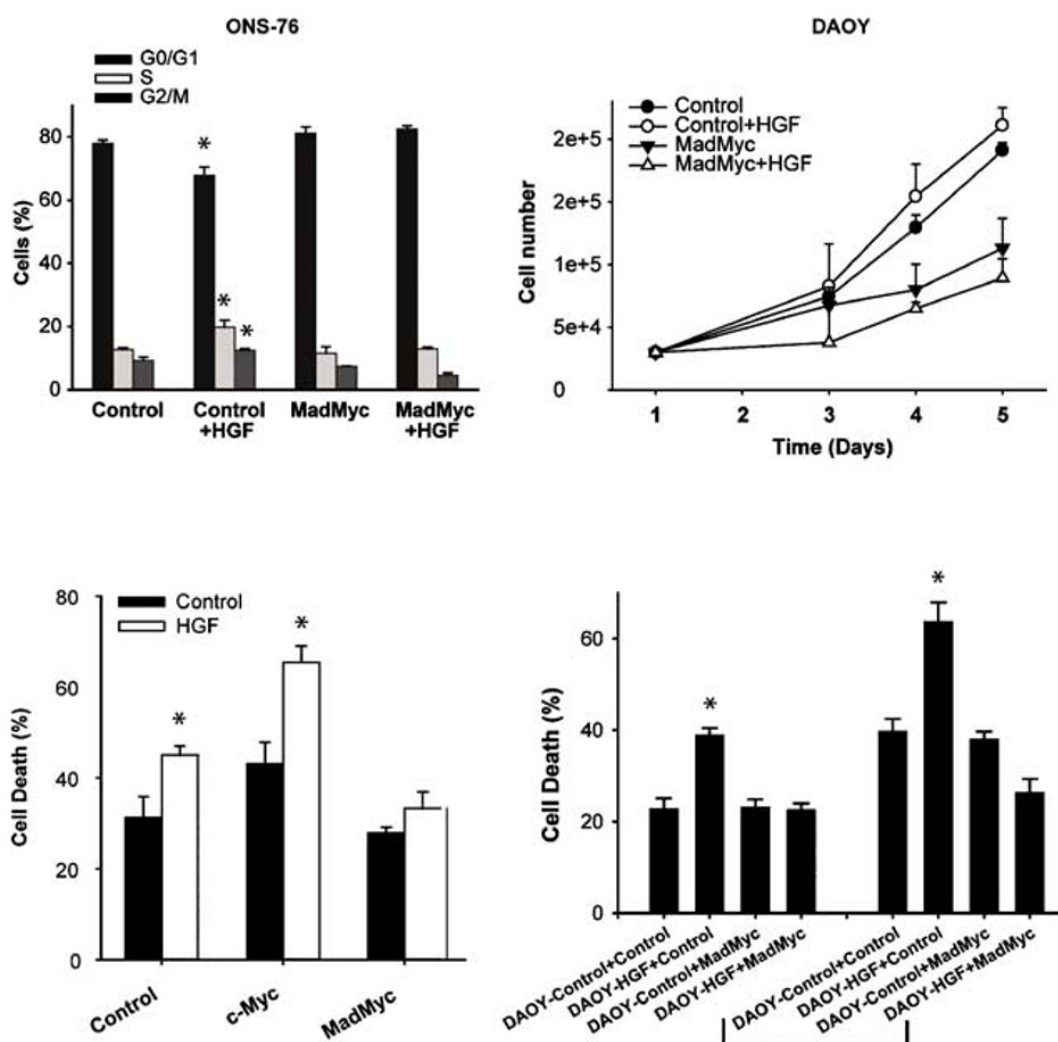

CPT, 250nM

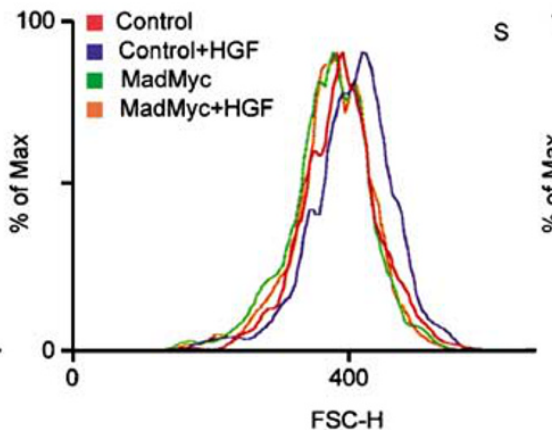

s

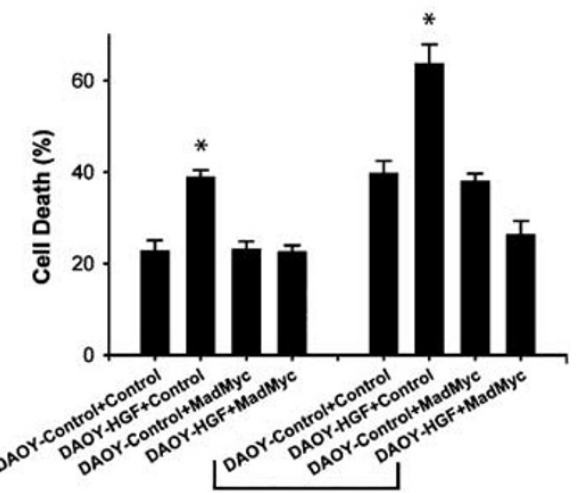

CPT, 250nM

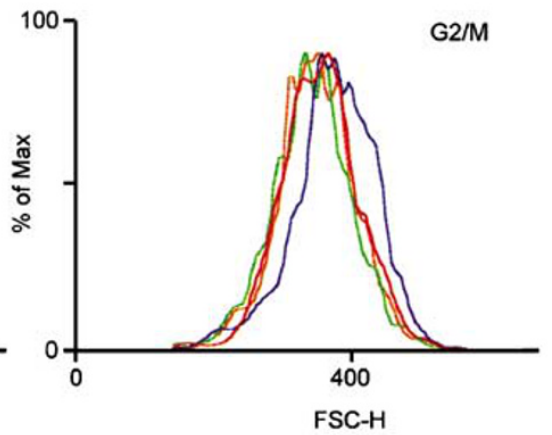


a

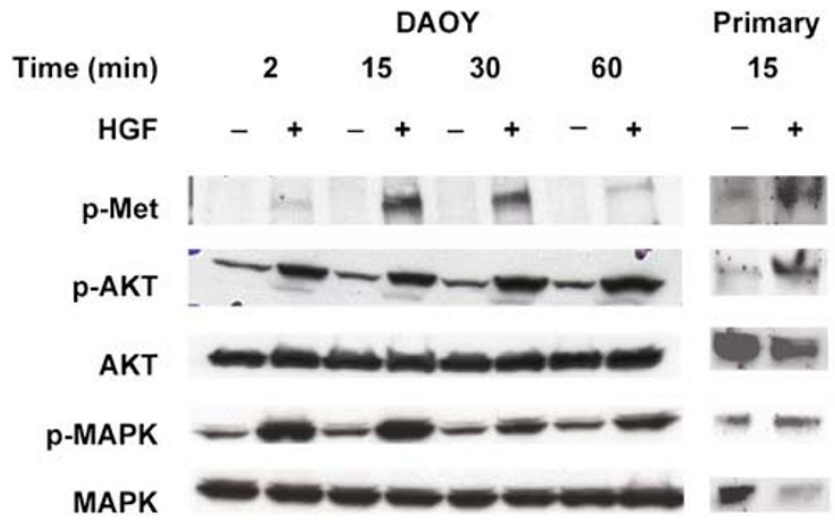

b
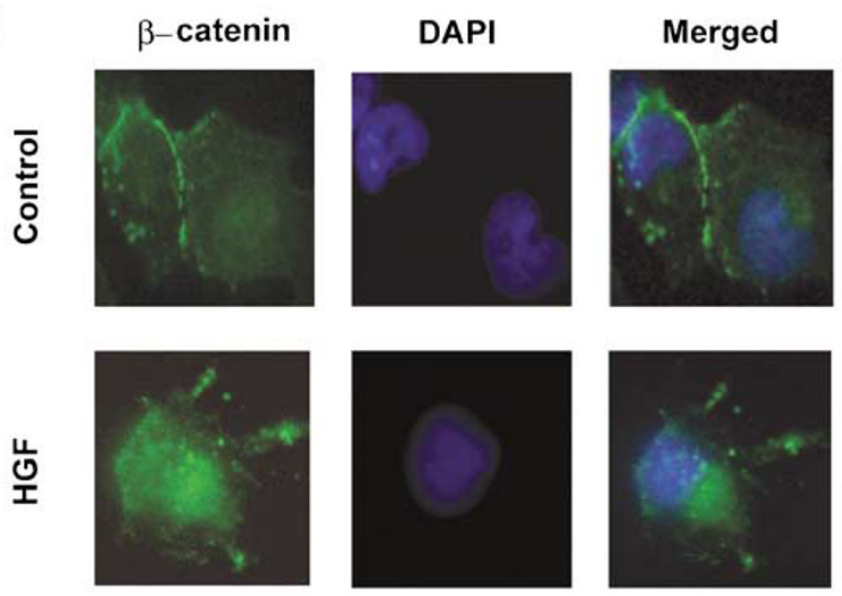

c

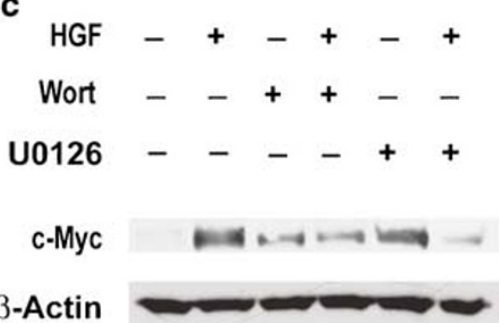

$\beta$-Actin

d

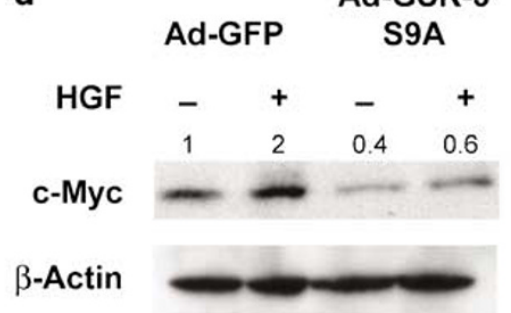

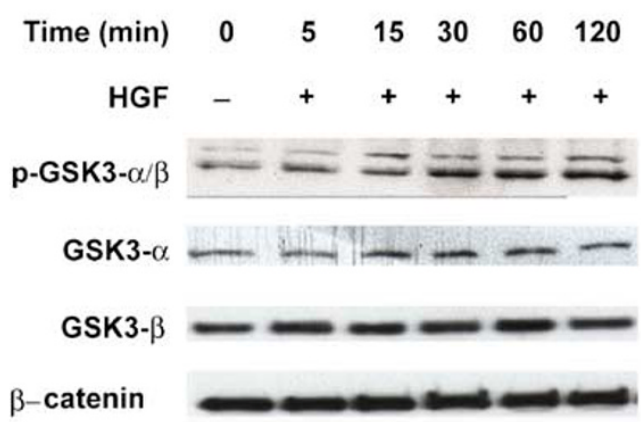

Figure 4 MAPK, PI3K/Akt, GSK-3 $\beta$ and $\beta$-catenin are involved in HGF-mediated induction of c-Myc. (a) DAOY and primary medulloblastoma cells were treated with HGF for various time points. Phospho-Met, phospho-Akt, phospho-MAPK and phospho-GSK $\alpha / \beta$ were analyzed by immunoblotting. The blots were also hybridized with total MAPK, total Akt and total GSK-3 as control. The results show that HGF induces the phosphorylation of c-Met, MAPK, Akt, GSK-3 $\alpha$ and GSK-3 $\beta$. (b) Immunofluorescent micrographs of DAOY cells treated with HGF for 30 min show redistribution of $\beta$-catenin from cell membrane to cytosol and nucleus as compared to control cells (left panel). Luciferase assay in DAOY cells transfected with Tcf-responsive luciferase reporter (Tcf), mutant Tcf-binding sites luciferase reporter (Tcf-Mut) or $\beta$-catenin expression plasmid (b-cat) prior to stimulation with HGF. The results show that HGF effectively induces Tcf-dependent luciferase activity relative to protein levels in the cells (right panel). (c) DAOY cells were treated with the MAPK pathway inhibitor U0126 or with the PI3K pathway inhibitor wortmannin prior to stimulation with HGF. Immunoblotting for c-Myc shows that HGF-mediated induction of c-Myc expression is completely inhibited by U0126 and wortmannin relative to control. (d) DAOY cells were infected with an adenovirus encoding the GSK-3 mutant S9A, constant GSK-3 $\beta$ activity or control (GFP) prior to stimulation with HGF. Quantitative immunoblotting for c-Myc shows that HGF-mediated induction of c-Myc expression is partially inhibited by overexpression of GSK-3 mutant S9A relative to control. (e) DAOY cells were transfected with Tcf/Lef transcription factor decoys that target Tcf/Lef-dependent transcriptional activity, or scrambled (control) prior to stimulation with HGF. Immunoblotting for c-Myc shows that HGF-mediated induction of c-Myc expression is partially inhibited by Tcf/Lef transcription factor decoys relative to scrambled decoys. Blots are representative from at least two different experiments. The numbers on the blots represent the average densitometric values of the bands relative to $\beta$-actin with control set at $1 .{ }^{\star} P<0.05$ relative to control.

inhibition of HGF-mediated induction of c-Myc in DAOY cells (Figure 4d). Inhibition of Tcf/Lef-dependent transcription activity in DAOY cells transfected with Tcf/Lef transcription factor decoys also led to the partial inhibition of
HGF-mediated induction of c-Myc in DAOY cells (Figure $4 \mathrm{e})$. These results show that MAPK, PI3K, GSK-3 and $\beta$ catenin are involved in HGF-mediated regulation of c-Myc levels in medulloblastoma cells. 


\section{Upregulation of Cdk2 Kinase Activity, Downregulation of Antiapoptotic BCl-XL Protein and Cleavage of Caspases 3 and 9 are Involved in Mediating the Effects of HGF on Cell Cycle and Apoptosis Downstream of c-Myc}

To determine the molecular mechanisms with which c-Myc mediates the effects of HGF on cell cycle progression in DAOY cells, the cell cycle-regulating proteins p27, Cdk2, E2F1 and cyclin $\mathrm{E}$ were examined by quantitative immunoblotting. These proteins were chosen based on our previous work that demonstrated their involvement in HGF-induced G1/S progression in medulloblastoma cells. ${ }^{4}$ Overexpression of MadMyc did not significantly change these cell cycle-related protein levels compared to control, and overexpression of MadMyc did not reverse HGF-induced reduction of p27 and induction of Cdk2 (Figure 5a). This shows that the effects of $\mathrm{c}-\mathrm{Myc}$ on the cell cycle are not mediated by the change of expression of the above-mentioned cell cycle regulatory proteins. We also assessed the effects of HGF-induced c-Myc on Cdk2/cyclin E complex formation using immunoprecipitation. Neither HGF treatment nor expression of MadMyc changed Cdk2 protein levels in cyclin E/Cdk2 immunoprecipitates, indicating that HGF and c-Myc effects on $\mathrm{G} 0 / \mathrm{G} 1$ progression are not due to changes in cyclin E/Cdk2 complex formation (Figure 5b). However, using a cyclin-dependent Cdk2 kinase activity assay, we found that HGF can activate Cdk2 kinase activity and that kinase activity is almost completely inhibited by overexpression of MadMyc (Figure 5b). Therefore, c-Myc mediates the effects of HGF on G0/G1 progression partly through modulation of Cdk2 kinase activity.

To further determine the molecular mechanisms with which c-Myc mediates the effects of HGF on apoptosis in DAOY cells, we first examined the effects of HGF and c-Myc on multiple apoptosis-regulating proteins. Using quantitative immunoblotting, we found that HGF enhances CPT-induced reduction of antiapoptotic Bcl-XL protein levels and increases activation of caspase- 9 and caspase- 3 and the cleavage of PARP in DAOY cells (Figure 5c). Overexpression of MadMyc reversed the change of these proteins induced by HGF and CPT. In the presence of MadMyc, HGF-induced reduction of Bcl-XL protein levels and activation of caspase9, caspase- 3 and PARP cleavage were inhibited as assessed by quantitative immunoblotting (Figure $5 \mathrm{c}$ ). These data indicate that c-Myc mediates the effects of HGF on apoptosis-regulating proteins in DAOY cells. We also found that treatment of DAOY cells with the broad-spectrum caspase inhibitor (Z-VAD-FMK) completely inhibited HGF-mediated induction of CPT-induced cell death (Figure 5d). This shows that HGF enhances CPT-induced DAOY apoptosis in a caspasedependent manner. To determine the role of Bcl-XL in HGFinduced and c-Myc-induced apoptosis, Bcl-XL was forcibly overexpressed in DAOY cells and the effects of HGF and c-Myc on apoptosis were analyzed by Annexin V-PE flow cytometry. Overexpression of Bcl-XL reduced the fraction of dead cells compared to control and significantly inhibited proapoptotic effect of HGF in DAOY cells $(n=3 ; P<0.05)$ (Figure 5d). This shows that downregulation of the antiapoptotic protein Bcl-XL is involved in mediating the proapoptotic effects of $\mathrm{HGF} / \mathrm{c}-\mathrm{Myc}$.

\section{HGF, c-Met, Akt, MAPK, $\beta$-Catenin, Cdk2 and Bcl-XL are Highly Expressed in Human Medulloblastoma Tumors}

To determine if key molecules that mediate the effects of HGF on c-Myc expression and functions are also expressed in human medulloblastoma tumors, we assessed protein expression of these molecules in medulloblastoma tissue arrays using immunohistochemistry. All 20 human large-cell medulloblastoma tumor sections present on the tissue array exhibited high to very high expression of all examined proteins as compared to normal human cerebellum control (Figure 6). These findings are consistent with the involvement of these molecules in HGF-induced c-Myc expression and function.

\section{DISCUSSION}

The present study describes for the first time a functional cooperation between $\mathrm{HGF} / \mathrm{c}-\mathrm{Met}$ and $\mathrm{c}-\mathrm{Myc}$ in human medulloblastoma malignancy and analyzes the molecular mechanisms that underlie this cooperation. The findings provide insight into the regulation of c-Myc expression in medulloblastoma and into the signal-transduction pathways and transcriptional events that mediate the effects of $\mathrm{HGF} / \mathrm{c}$ Met in these tumors (Figure 7).

We used two medulloblastoma cell lines and primary medulloblastoma cells in the study. All cells were used to show c-Myc induction by HGF. The dependency of HGFinduced cell cycle progression on c-Myc was demonstrated in DAOY and ONS-76 cells and the dependency of HGF-induced apoptosis on c-Myc was demonstrated in DAOY cells (HGF does not induce apoptosis in ONS-76 cells). The signal-transduction pathways and transcriptional events that mediate the effects of HGF/c-Met on c-Myc were studied in DAOY cells and a few key findings were confirmed in primary medulloblastoma due to the limited availability of the latter.

We first observed relative histological similarities between DAOY-HGF xenografts and DAOY-c-Myc xenografts. These similarities are also shared with the large-cell anaplastic medulloblastoma subtype and are characterized by large, round neoplastic cells with increased nuclear size and nuclei that are also large with markedly atypical and irregular shapes. The large-cell anaplastic phenotype has been associated with $c-M y c$ amplification and represents the most malignant medulloblastoma subtype. ${ }^{22,29}$ Here, we provide a potential explanation for this observation and study its molecular basis.

Our study identifies HGF as a potent regulator of c-Myc expression in medulloblastoma. In addition to other regulatory mechanisms of c-Myc reported in medulloblastoma, 
a

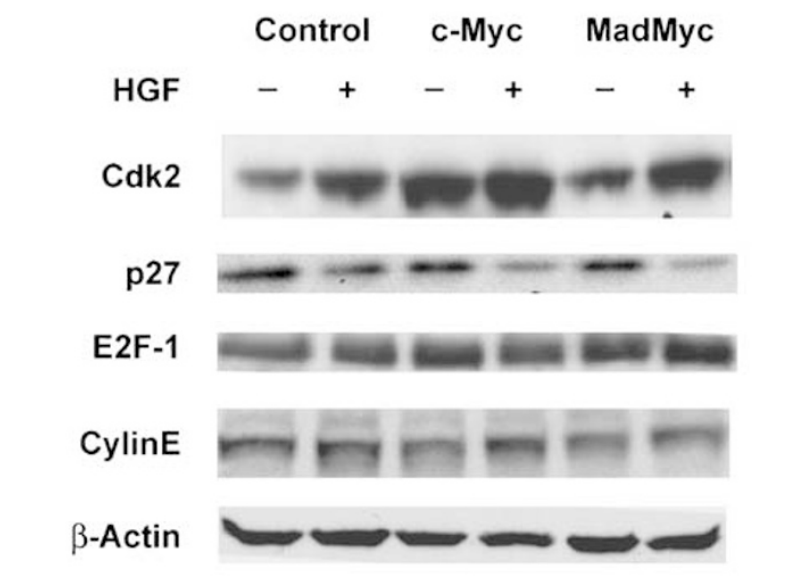

C

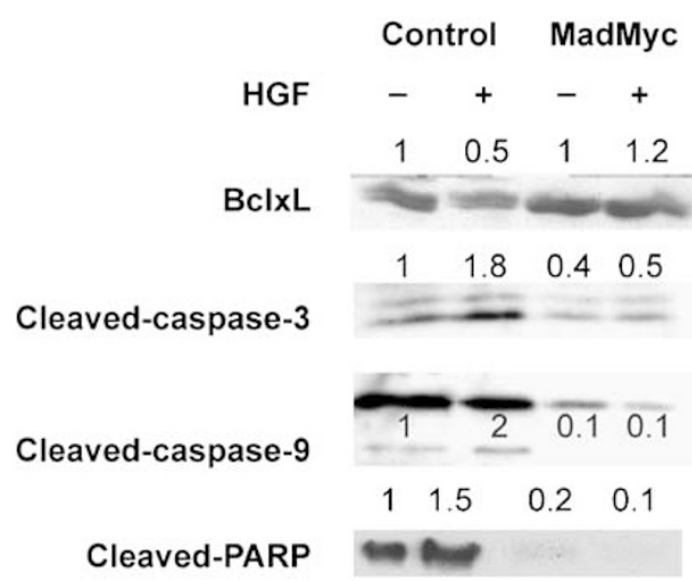

Cleaved-PARP
CPT $(0.5 \mu \mathrm{M})$

$\beta$-Actin

d

IP: Cyclin E

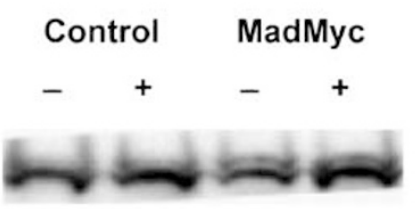

IB: Cdk2

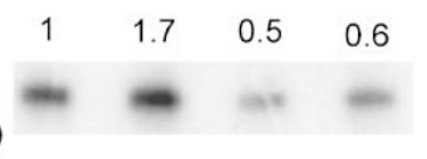

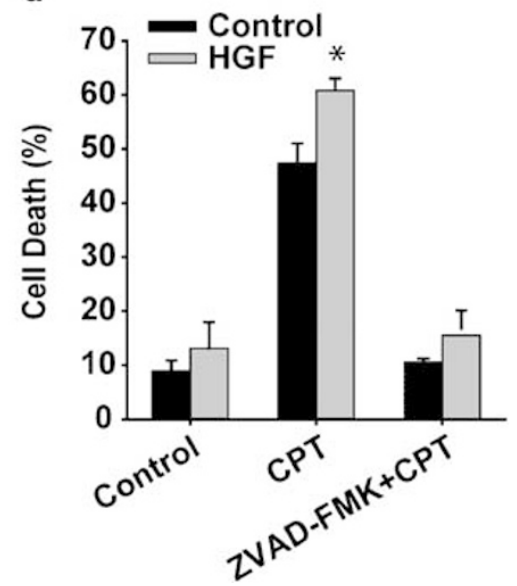

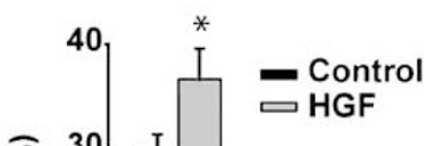
•HGF

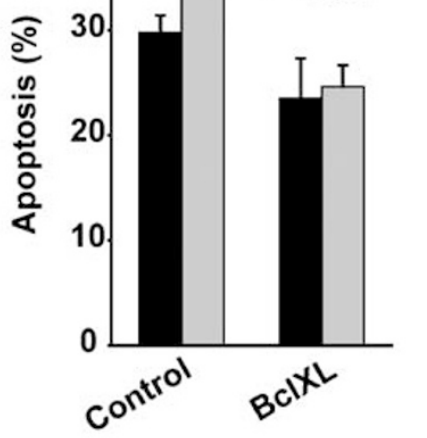

Figure 5 Upregulation of Cdk2 kinase activity, downregulation of antiapoptotic Bcl-XL protein and cleavage of caspases 3 and 9 are involved in mediating the effects of HGF on cell cycle and apoptosis downstream of c-Myc. (a) DAOY cells were infected with adenoviruses encoding c-Myc, MadMyc or control (GFP) prior to stimulation with HGF. Cell cycle-regulating proteins p27, Cdk2, E2F-1 and cyclin E were examined by immunoblotting. The results show that overexpression of MadMyc does not reverse HGF-mediated reduction of p27 and induction of Cdk2. (b) Cyclin E/Cdk2 complexes were immunoprecipitated (IP) with an anti-cyclin E antibody from lysates of DAOY cells treated as described in 'panel a'. The immunoprecipitates were immunoblotted (IB) for Cdk2. The immunoprecipitates were also subjected to in vitro kinase assays with histone $\mathrm{H} 1$ as substrate. The results show that overexpression of MadMyc partially inhibits HGF-mediated induction of Cdk2 kinase activity but not Cdk2 complex binding to cyclin E. (c) DAOY cells were infected with adenoviruses expressing MadMyc or control (GFP) before treatment with HGF and CPT (500 nM). Bcl-XL, cleaved-caspase-3, cleaved-caspase- 9 and cleaved-PARP protein levels were examined by immunoblotting. The results show that overexpression of MadMyc inhibits the effects of HGF on Bcl-XL, caspase-3, caspase-9 and cleaved-PARP protein levels. (d) DAOY cells were treated with the pan-caspase inhibitor (Z-VAD-FMK, $100 \mu \mathrm{M})$ prior to stimulation with HGF and treatment with CPT ( $250 \mathrm{nM})$. The dead cells were analyzed by LDH assay, which shows that cell death induced by HGF is completely inhibited by Z-VAD-FMK (left panel). DAOY cells were cotransfected with Bcl-XL and GFP constructs prior to stimulation with HGF and treatment with CPT $(250 \mathrm{nM})$. Flow cytometric analysis of GFP-positive and PI-labeled transfected cells shows that the proapoptotic effects of HGF are

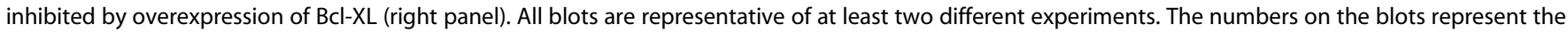
average densitometric values of the bands relative to $\beta$-actin with control set at $1 .{ }^{\star} P<0.05$ relative to control.

such as genomic amplification of $c-M y c$, mutation of adenomatous polyposis coli (APC) gene and $\beta$-catenin, ${ }^{30-33}$ HGF or c-Met overexpression represents a new mechanism that could explain the high levels of $\mathrm{c}-\mathrm{Myc}$ in these tumors. In our study, HGF strongly induced c-Myc expression levels in all medulloblastoma cells that we tested. The transient nature of HGF-induced c-Myc expression is probably due to the transient application of recombinant HGF in vitro. Recombinant HGF has a finite life and c-Myc has a short halflife. Therefore, when recombinant HGF is degraded HGFinduced c-Myc levels decrease. However, the above does not apply for human medulloblastoma tumors. We previously reported that HGF and c-Met are frequently overexpressed in human medulloblastoma. Therefore, unlike in vitro where 

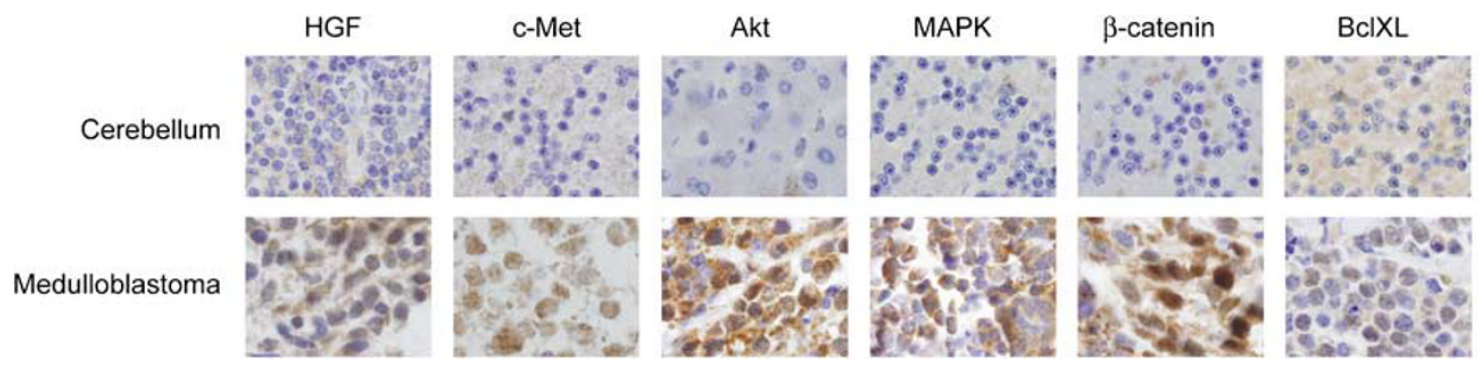

Cdk2

Figure 6 Human medulloblastoma tissue arrays were immunostained for HGF, c-Met, Akt, MAPK, $\beta$-catenin, Cdk2 and Bcl-XL. Protein expression in the tumors was compared to expression in normal human cerebellum. The slides ( $\times 100$ magnification $)$ show representative sections showing high to very high expression of all examined proteins in tumors as compared to normal cerebellum.

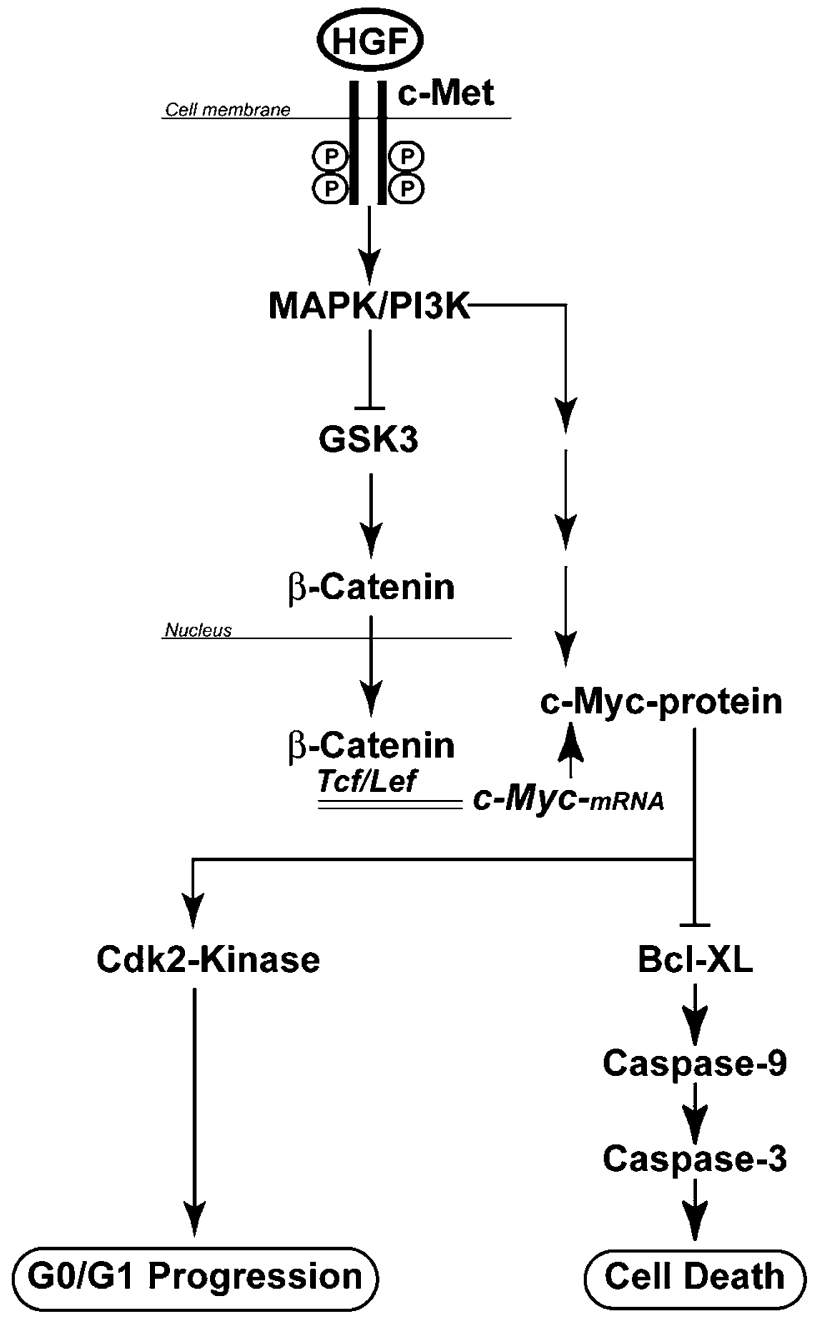

Figure 7 Overview of the signaling pathways and transcriptional events that are involved in mediating the effects of HGF and c-Myc in medulloblastoma.

HGF is added to the cells as one single application, HGF is constantly produced in vivo. This could lead to constant activation of c-Met and subsequently constant overexpression of c-Myc. HGF induced c-Myc expression via both transcriptional and post-transcriptional mechanisms. The transcriptional mechanisms are evidenced by the increase in
c-Myc mRNA and the activation of $c-M y c$ promoter activity by HGF. The post-transcriptional mechanisms are evidenced by the ability of HGF to still induce c-Myc protein after inhibition of protein synthesis and mRNA transcription. This is further supported the early increase in c-Myc protein, which starts at least as early as the increase in mRNA and by the HGF-mediated stabilization of exogenous c-Myc protein.

The molecular events that regulate c-Myc expression in human medulloblastoma are poorly understood. Our study identifies some of the signal-transduction pathways and transcriptional events that are involved in c-Myc expression regulation by HGF in medulloblastoma. We show that activation of c-Met-, MAPK-, PI3K-, GSK-3- and $\beta$-catenin/Tcf/ Lef-dependent transcription induced by HGF is involved in HGF induction of c-Myc expression. At the functional level, this study shows that c-Myc mediates G0/G1 cell cycle progression in DAOY and ONS-76 cells as well as the cytotoxic effects of HGF in DAOY cells. Cooperation between c-Met and c-Myc has been shown in vivo in breast cancer. ${ }^{34}$ Using a different approach, the authors found that overexpression of c-Met resulted in the development of multiple microscopic foci of neoplasia that failed to progress to full-blown malignancies. But an additional genetic stimulus, overexpression of c-Myc, cooperated with c-Met in mammary tumorigenesis. These in vivo findings, which did not examine the molecular interactions between c-Met and c-Myc, are consistent with and supportive of our findings. HGF has antiapoptotic and cytoprotective effects in many human tumors. ${ }^{35-41}$ We also previously found that HGF has antiapoptotic effects in ONS76 cells. However, proapoptotic effects of HGF have also been reported in some types of cancer cells. This latter is demonstrated in our study where HGF enhanced chemotherapy- and radiation-induced apoptosis of DAOY cells. HGF has been shown to induce apoptosis in a sarcoma cell line and in liver carcinoma models. ${ }^{42-45}$ HGF activates apoptosis signaling pathways by enhancing the production of ROS and increasing the activity of caspase- 3 in Sarcoma 180 cells. $^{46}$ Furthermore, HGF can sensitize ovarian carcinoma cells to CDDP- and PTX-induced apoptosis through a caspase-dependent apoptotic pathway. ${ }^{47}$ Taken together, the induction of cell cycle progression and cell proliferation as well as apoptosis by HGF via c-Myc in DAOY cells are consistent 
with our in vivo data that show a marked increase in mitotic rates and extensive apoptosis displayed in DAOY-HGF xenografts, characteristics that are also seen in large-cell anaplastic human tumors. These observations further suggest that the cooperation between the HGF/c-Met pathway and c-Myc in human medulloblastoma might lead to the formation of the most malignant large-cell anaplastic medulloblastomas.

In the present study, we also analyzed the mechanisms that mediate the functional effects of HGF in medulloblastoma downstream of c-Myc. We have previously shown that HGF induces cell cycle progression in medulloblastoma via inhibition of the levels of tumor suppressor p27 and induction of Cdk2 and E2F-1 expression. ${ }^{4}$ c-Myc inhibition in DAOY medulloblastoma cells did not affect the expression levels of these cell cycle regulators. Also, c-Myc inhibition did not alter Cdk2 protein levels in cyclin E/Cdk2 complexes. However, c-Myc inhibition did inhibit cyclin-dependent kinase activity induced by HGF. These findings are consistent with previous literature that showed that inhibition of c-Myc with MadMyc in NIH3T3 cells did not cause alterations in the expression levels of cyclin E, Cdk2, p27, cyclin D1 or Cdk4, but that the MadMyc-induced G1 arrest was associated with a strong reduction in cyclin E/Cdk2 kinase activity. ${ }^{48}$ Our previous finding that HGF regulates cell cycle progression in medulloblastoma is mediated by changes in the expression of p27 and Cdk2 combined with our present findings that c-Myc-mediated HGF-induced G1 progression is not caused by changes in p27 and Cdk2 expression indicate that HGFmediated induction of cell cycle progression in medulloblastoma has c-Myc-dependent as well as c-Myc-independent components. This could explain the partial inhibition of HGF-induced cell cycle progression and proliferation after inhibition of c-Myc as observed in our study.

In this study, we also show that the proapoptotic effects of HGF are mediated by c-Myc in part via downregulation of $\mathrm{Bcl}-\mathrm{XL}$ in DAOY cells. Interestingly, HGF was cytoprotective in other medulloblastoma cells that possess dramatically higher Bcl-XL levels compared to DAOY cells. HGF induced $\mathrm{c}-\mathrm{Myc}$ in these cell lines but was unable to downregulate the high Bcl-XL levels of these cells (data not shown). The proapoptotic effects of HGF could therefore depend on Bcl$\mathrm{XL}$ expression levels in the cells, which when constitutively high cannot be downregulated by c-Myc induction. c-Mycinduced apoptosis regulated by Bcl-XL has been reported in other cell types. In mouse embryo fibroblasts, c-Myc sensitizes the cells to $\gamma$-radiation via suppression of Bcl-XL expression. Restoration of Bcl-XL protects Myc-expressing cells from $\gamma$-radiation-induced apoptosis. ${ }^{49} \mathrm{c}$-Myc activation also suppresses Bcl-XL mRNA and protein levels in cultures of primary myeloid and lymphoid progenitors. ${ }^{50}$

In summary, we show for the first time that the c-Met pathway regulates c-Myc levels and that c-Myc mediates the effects of c-Met in medulloblastoma. We elucidate the molecular mechanisms of $\mathrm{c}-\mathrm{Myc}$ regulation by $\mathrm{c}-\mathrm{Met}$ and of the coregulation of medulloblastoma cell proliferation, apoptosis and cell size by c-Met and c-Myc. The findings provide an explanation for the high frequency of c-Myc overexpression in medulloblastoma and suggest a cooperative role for c-Met and c-Myc in large-cell anaplastic medulloblastoma formation.

\section{ACKNOWLEDGEMENT}

This study was supported by NIH Grant RO1 NS045209 (RA), RO1 NS32148 $(\mathrm{JL})$ and the Jean Maxwell/American Brain Tumor Association Fellowship $(\mathrm{YL})$.

1. Taylor MD, Mainprize TG, Rutka JT. Molecular insight into medulloblastoma and central nervous system primitive neuroectodermal tumor biology from hereditary syndromes: a review. Neurosurgery 2000;47:888-901.

2. Wechsler-Reya R, Scott MP. The developmental biology of brain tumors. Annu Rev Neurosci 2001;24:385-428.

3. Newton HB. Review of the molecular genetics and chemotherapeutic treatment of adult and paediatric medulloblastoma. Expert Opin Investig Drugs 2001;10:2089-2104.

4. Li Y, Lal B, Kwon S, et al. The scatter factor/hepatocyte growth factor: c-met pathway in human embryonal central nervous system tumor malignancy. Cancer Res 2005;65:9355-9362.

5. Schmidt EV. The role of c-myc in cellular growth control. Oncogene 1999;18:2988-2996.

6. Henriksson $M$, Luscher B. Proteins of the Myc network: essential regulators of cell growth and differentiation. Adv Cancer Res 1996;68:109-182.

7. Obaya AJ, Mateyak MK, Sedivy JM. Mysterious liaisons: the relationship between c-Myc and the cell cycle. Oncogene 1999;18:2934-2941.

8. Facchini LM, Penn LZ. The molecular role of Myc in growth and transformation: recent discoveries lead to new insights. FASEB J 1998;12:633-651.

9. Bouchard C, Staller P, Eilers M. Control of cell proliferation by Myc. Trends Cell Biol 1998;8:202-206.

10. Grotzer MA, Hogarty MD, Janss AJ, et al. MYC messenger RNA expression predicts survival outcome in childhood primitive neuroectodermal tumor/medulloblastoma. Clin Cancer Res 2001;7:2425-2433.

11. Batra SK, McLendon RE, Koo JS, et al. Prognostic implications of chromosome 17p deletions in human medulloblastomas. J Neurooncol 1995;24:39-45.

12. Herms J, Neidt I, Luscher B, et al. C-MYC expression in medulloblastoma and its prognostic value. Int J Cancer 2000;89: 395-402.

13. Eberhart CG, Kratz J, Wang $Y$, et al. Histopathological and molecular prognostic markers in medulloblastoma: c-myc, N-myc, TrkC, and anaplasia. J Neuropathol Exp Neurol 2004;63:441-449.

14. Aldosari N, Bigner SH, Burger PC, et al. MYCC and MYCN oncogene amplification in medulloblastoma. A fluorescence in situ hybridization study on paraffin sections from the Children's Oncology Group. Arch Pathol Lab Med 2002;126:540-544.

15. Bigner $\mathrm{SH}$, Friedman HS, Vogelstein B, et al. Amplification of the c-myc gene in human medulloblastoma cell lines and xenografts. Cancer Res 1990;50:2347-2350.

16. Batra SK, Rasheed BK, Bigner SH, et al. Oncogenes and anti-oncogenes in human central nervous system tumors. Lab Invest 1994;71:621-637.

17. Chiariello M, Marinissen MJ, Gutkind JS. Regulation of c-myc expression by PDGF through Rho GTPases. Nat Cell Biol 2001;3: 580-586.

18. lavarone C, Catania A, Marinissen MJ, et al. The platelet-derived growth factor controls c-myc expression through a JNK- and AP-1-dependent signaling pathway. J Biol Chem 2003;278:50024-50030.

19. Izadnegahdar MF, Rathanaswami P, Shah RM. Effects of EGF and TGFbeta1 on c-myc gene expression and DNA synthesis in embryonic hamster palate mesenchymal cells. Anat Rec 1999;254:453-464.

20. Taniguchi $F$, Harada T, Sakamoto $Y$, et al. Activation of mitogenactivated protein kinase pathway by keratinocyte growth factor or 
fibroblast growth factor-10 promotes cell proliferation in human endometrial carcinoma cells. J Clin Endocrinol Metab 2003;88:773-780.

21. Stearns D, Chaudhry A, Abel TW, et al. c-myc overexpression causes anaplasia in medulloblastoma. Cancer Res 2006;66:673-681.

22. Brown HG, Kepner JL, Perlman EJ, et al. 'Large cell/anaplastic' medulloblastomas: a Pediatric Oncology Group Study. J Neuropathol Exp Neurol 2000;59:857-865.

23. da Costa LT, He TC, Yu J, et al. CDX2 is mutated in a colorectal cancer with normal APC/beta-catenin signaling. Oncogene 1999;18: 5010-5014.

24. He TC, Sparks AB, Rago $C$, et al. Identification of $c-M Y C$ as a target of the APC pathway. Science 1998;281:1509-1512.

25. Abounader R, Ranganathan S, Lal B, et al. Reversion of human glioblastoma malignancy by U1 small nuclear RNA/ribozyme targeting of scatter factor/hepatocyte growth factor and c-met expression. J Natl Cancer Inst 1999:91:1548-1556.

26. Hermeking $H$, Rago $C$, Schuhmacher $M$, et al. Identification of CDK4 as a target of c-MYC. Proc Natl Acad Sci USA 2000;97: 2229-2234.

27. Sanchez JF, Sniderhan LF, Williamson AL, et al. Glycogen synthase kinase 3beta-mediated apoptosis of primary cortical astrocytes involves inhibition of nuclear factor kappaB signaling. Mol Cell Biol 2003; 23:4649-4662.

28. Eberhart CG, Kratz JE, Schuster A, et al. Comparative genomic hybridization detects an increased number of chromosomal alterations in large cell/anaplastic medulloblastomas. Brain Pathol 2002;12:36-44.

29. Leonard JR, Cai DX, Rivet DJ, et al. Large cell/anaplastic medulloblastomas and medullomyoblastomas: clinicopathological and genetic features. J Neurosurg 2001;95:82-88.

30. Zurawel RH, Chiappa SA, Allen $\mathrm{C}$, et al. Sporadic medulloblastomas contain oncogenic beta-catenin mutations. Cancer Res 1998;58: 896-899.

31. Huang $H$, Mahler-Araujo BM, Sankila A, et al. APC mutations in sporadic medulloblastomas. Am J Pathol 2000;156:433-437.

32. Koch A, Waha A, Tonn JC, et al. Somatic mutations of WNT/wingless signaling pathway components in primitive neuroectodermal tumors. Int J Cancer 2001;93:445-449.

33. Eberhart CG, Tihan T, Burger PC. Nuclear localization and mutation of beta-catenin in medulloblastomas. J Neuropathol Exp Neurol 2000;59:333-337.

34. Welm AL, Kim S, Welm BE, et al. MET and MYC cooperate in mammary tumorigenesis. Proc Natl Acad Sci USA 2005;102:4324-4329.

35. Fan S, Wang JA, Yuan RQ, et al. Scatter factor protects epithelial and carcinoma cells against apoptosis induced by DNA-damaging agents. Oncogene 1998:17:131-141.

36. Meng $Q$, Mason JM, Porti $D$, et al. Hepatocyte growth factor decreases sensitivity to chemotherapeutic agents and stimulates cell adhesion, invasion, and migration. Biochem Biophys Res Commun 2000;274 772-779.

37. Gao M, Fan S, Goldberg ID, et al. Hepatocyte growth factor/scatter factor blocks the mitochondrial pathway of apoptosis signaling in breast cancer cells. J Biol Chem 2001;276:47257-47265.

38. Bowers DC, Fan S, Walter KA, et al. Scatter factor/hepatocyte growth factor protects against cytotoxic death in human glioblastoma via phosphatidylinositol 3-kinase- and AKT-dependent pathways. Cancer Res 2000;60:4277-4283.

39. Mildner M, Eckhart L, Lengauer B, et al. Hepatocyte growth factor/ scatter factor inhibits UVB-induced apoptosis of human keratinocytes but not of keratinocyte-derived cell lines via the phosphatidylinositol 3-kinase/AKT pathway. J Biol Chem 2002;277:14146-14152.

40. Bardelli $A$, Longati $P$, Albero $D$, et al. HGF receptor associates with the anti-apoptotic protein BAG-1 and prevents cell death. EMBO J 1996;15:6205-6212.

41. Xiao GH, Jeffers $M$, Bellacosa $A$, et al. Anti-apoptotic signaling by hepatocyte growth factor/Met via the phosphatidylinositol 3-kinase/ Akt and mitogen-activated protein kinase pathways. Proc Natl Acad Sci USA 2001;98:247-252.

42. Conner EA, Wirth PJ, Kiss A, et al. Growth inhibition and induction of apoptosis by HGF in transformed rat liver epithelial cells. Biochem Biophys Res Commun 1997;236:396-401.

43. Shima N, Nagao $M$, Ogaki $F$, et al. Tumor cytotoxic factor/hepatocyte growth factor from human fibroblasts: cloning of its CDNA, purification and characterization of recombinant protein. Biochem Biophys Res Commun 1991;180:1151-1158.

44. Arakaki N, Kajihara T, Arakaki R, et al. Involvement of oxidative stress in tumor cytotoxic activity of hepatocyte growth factor/scatter factor. J Biol Chem 1999;274:13541-13546.

45. Matteucci E, Castoldi R, Desiderio MA. Hepatocyte growth factor induces pro-apoptotic genes in HepG2 hepatoma but not in B16-F1 melanoma cells. J Cell Physiol 2001;186:387-396.

46. Arakaki N, Kazi JA, Kazihara T, et al. Hepatocyte growth factor/scatter factor activates the apoptosis signaling pathway by increasing caspase-3 activity in sarcoma 180 cells. Biochem Biophys Res Commun 1998;245:211-215.

47. Rasola A, Anguissola S, Ferrero N, et al. Hepatocyte growth factor sensitizes human ovarian carcinoma cell lines to paclitaxel and cisplatin. Cancer Res 2004;64:1744-1750.

48. Berns K, Hijmans EM, Bernards R. Repression of c-Myc responsive genes in cycling cells causes $\mathrm{G} 1$ arrest through reduction of cyclin E/CDK2 kinase activity. Oncogene 1997;15:1347-1356.

49. Maclean KH, Keller UB, Rodriguez-Galindo C, et al. c-Myc augments gamma irradiation-induced apoptosis by suppressing BCl-XL. Mol Cell Biol 2003;23:7256-7270.

50. Eischen $\mathrm{CM}$, Packham G, Nip J, et al. Bcl-2 is an apoptotic target suppressed by both c-Myc and E2F-1. Oncogene 2001;20:6983-6993. 